\title{
ORIENTASI HAPPINESS PADA ORANG TUA YANG MEMILIKI ANAK TUNAGRAHITA RINGAN
}

\author{
Tri Na’imah, Nur’aeni, Dyah Siti Septiningsih \\ Fakultas Psikologi - Universitas Muhammadiyah Purwokerto \\ J1. Raya Dukuhwaluh PO BOX 202 Purwokerto \\ trien.psikologi@gmail.com
}

\begin{abstract}
The purposes of this study were: 1) assess the orientation of happiness in mothers of children with mild mental retardation, 2) assess the orientation of happiness in the fathers who have children with mild mental retardation. This study is a qualitative study using phenomenological approach. The primary informants are mothers and fathers who have mild mentally disabled children who attend school in SLB C Yakut Purwokerto, while the secondary informants were neighbors. Methods of data collection in this study is the interview. Analysis of the data used interactive model analysis. The results showed: There are differences in the pattern of happiness orientation between the mother and father who have children with mild mental retardation. Orientation mother more happiness are dominated on social engagement, meaning that mother happier if it can be involved in social activities. While the pursuit of happiness if dad can do something fun that is the way the economic needs of the family.
\end{abstract}

Keywords: orientation happiness; parents; mild mental retardation

\begin{abstract}
Abstrak
Tujuan dari penelitian ini adalah: 1) Mengkaji orientasi kebahagiaan ibu dari anak-anak dengan retardasi mental ringan, 2) Mengkaji orientasi kebahagiaan ayah yang memiliki anak dengan tungrahita ringan. Penelitian ini merupakan penelitian kualitatif dengan menggunakan pendekatan fenomenologis. Informan primer adalah ibu dan ayah yang memiliki ringan anak-anak cacat mental yang bersekolah di SLB C Yakut Purwokerto, sedangkan informan sekunder adalah tetangga. Metode pengumpulan data dalam penelitian ini adalah wawancara. Analisis data yang digunakan analisis model interaktif. Hasil penelitian menunjukkan: Ada perbedaan dalam pola orientasi kebahagiaan antara ayah dan ibu yang memiliki anak dengan tunagrahita mental ringan. Orientasi happiness ibu lebih didominasi pada keterlibatan sosial,, berarti ibu yang lebih bahagia jika dapat terlibat dalam kegiatan sosial. Sementara pencapaian kebahagiaan jika ayah bisa dengan melakukan sesuatu yang menyenangkan yaitu dengan cara kebutuhan ekonomi keluarga.
\end{abstract}

Kata kunci: orientasi happiness; orangtua; tunagrahita ringan

\section{PENDAHULUAN}

Setiap orangtua tentunya mengharapkan memiliki anak dalam kondisi sehat secara fisik maupun psikologis. Namun, kenyataannya anak yang lahir tidak semua dalam kondisi sehat baik fisik maupun mental, sehingga dapat digolongkan sebagai anak berkebutuhan khusus. Salah satu bentuk kelainan yang bisa terjadi adalah tunagrahita.

Reaksi orangtua yang pertama kali muncul pada saat mengetahui bahwa anaknya mengalami kelainan adalah perasaan shock, mengalami goncangan batin, terkejut dan tidak mempercayai kenyataan yang menimpa anaknya (Mangunsong, 2011). Orangtua yang memiliki anak tungrahita sering mengalami masalah dalam pengasuhannya. Orangtua harus mengorbankan banyak waktu untuk bekerja demi memberikan perhatian ekstra dan perhatian khusus untuk merawat anak tunagrahita. Keluarga membutuhkan waktu, tenaga dan pikiran yang lebih banyak untuk merawat anak tunagrahita karena fungsi kecerdasan dan kemampuan tingkah laku adaptif anak tunagrahita terbatas. Orangtua yang memiliki anak tunagrahita menunjukkan perasaan sedih, depresi, marah 
dan kurang menerima keadaan anaknya. Orangtua merasa khawatir tentang masa depan anak dan stigma yang melekat pada anak. Berbagai masalah yang dialami orangtua yang memiliki anak tunagrahita bisa menurunkan happiness dalam hidupnya.

Kebahagiaan merupakan tujuan hidup yang penting, karena kebahagiaan merupakan salah satu dimensi yang penting dari kehidupan emosional manusia. Selain itu, kebahagiaan dapat menghasilkan banyak manfaat bagi individu, oleh karenanya dapat membentuk kehidupan masyarakat yang lebih baik. Kebahagiaan berkaitan secara positif dengan perilaku dan atribut yang positif, seperti sosialisasi, perilaku prososial, persepsi positif terhadap diri dan orang lain, coping, dan kreativitas (Lyubomirsky, 2007).

Dalam penelitian ini dibatasi kategori anak tunagrahita pada tunagrahita ringan. Menurut Soemantri (2007) tunagrahita ringan disebut juga moron atau debil. Kelompok ini memiliki IQ antara 68 - 52 menurut skala Binet, sedangkan menurut skala Wischler (WISC) memiliki IQ 69-55. Mereka masih bisa belajar membaca, menulis dan berhitung sederhana dan memiliki kemampuan sosial tetapi sering terjadi hambatan komunikasi. Dengan bimbingan dan pendidikan yang baik dari orangtua anak tunagrahita ringan dapat dididik menjadi tenaga kerja semi-skilled, bahkan jika dilatih dan dibimbing dengan baik dapat bekerja dengan sedikit pengawasan. Keberhasilan orang tua dalam menjalankan parenting dan co parenting itulah yang akan membentuk kebahagiaan (happiness) nya.

Banyak pikiran negatif yang muncul pada orangtua saat mengetahui bahwa anaknya memiliki ketidaksempurnaan, seperti rasa bersalah, kehilangan, ketakutan akan masa depan, stigma negatif dari masyarakat (Williams \& Wright, 2004). Hasil penelitian yang dilakukan oleh Hamid (2004) juga menunjukkan bahwa orang tua yang memiliki anak tunagrahita menunjukkan perasaan sedih, depresi, marah dan kurang menerima keadaan anaknya. Orang tua merasa khawatir tentang masa depan anak dan stigma yang melekat pada anak.

Dalam pengasuhan anak ayah turut memberikan kontribusi penting bagi perkembangan anak, pengalaman yang dialami bersama dengan ayah, akan mempengaruhi seorang anak hingga dewasa nantinya. Peran serta perilaku pengasuhan ayah mempengaruhi perkembangan serta kesejahteraan anak dan masa transisi menuju remaja (Cabrera,dkk., 2000). Dalam pendidikan di keluarga ibu dipandang sebagai sosok yang paling dekat dengan anak (Cohen \& Volkmar, 1997). Ibu yang lebih sering menghadapi situasi-situasi yang tidak menyenangkan, seperti hubungan sosial anak yang terganggu, gangguan perkembangan dalam komunikasi dan lain sebagainya (Knoer \&Haditono, 1999). Hasil penelitian Na'imah \& Septiningsih (2015) di SLB C Yakut Purwokerto menunjukkan bahwa antara ayah dan ibu sering memberi perlakuan yang berbeda terhadap anak tuna grahita, sehingga menyebabkan anak kebingungan dalam memilih role model.

Ada berbagai pendekatan dalam usaha untuk memahami arti kebahagiaan dan darimana sumber kebahagiaan tersebut, misalnya pendekatan biologis, psikologis, agama, dan filsafat. Selain itu, para peneliti juga telah mengidentifikasi beberapa atribut yang berkorelasi dengan kebahagiaan diantaranya adalah interaksi sosial, status perkawinan, pekerjaan, kesehatan, kebebasan demokrasi, optimisme, keterlibatan dalam kegiatan agama, dan pendapatan ekonomi.

Furnham \& Fudge (2008) juga menyatakan bahwa kebahagiaan merupakan bagian dari kesejahteraan, kesenangan, kepuasan hati, dan berkurangnya stres dalam hidup. Diener \& Oishi (2005) menyatakan bahwa kepuasan hidup merupakan bentuk nyata dari kebahagiaan dimana kebahagiaan tersebut merupakan sesuatu yang dihubungkan dengan kesehatan yang lebih baik, kreativitas yang lebih tinggi serta tempat kerja yang 
lebih baik, sebagaimana dikatakan Seligman (2002) bahwa happiness (kebahagiaan) merupakan emosi dan aktivitas positif. Berdasarkan uraian tersebut, maka dapat dikatakan bahwa kebahagiaan tidak diarahkan pada kondisi tertentu saja tetapi kebahagiaan merupakan dimilikinya emosi positif dalam keseluruhan dari kehidupan manusia.

Kebahagiaan seseorang dipengaruhi faktor eksternal dan faktor internal. Faktor eksternal antara lain uang, pernikahan, kehidupan sosial, produktifitas kerja, pendidikan, iklim, ras dan jender. Sedangkan faktor internal antara lain kesehatan, usia, keadaan emosi, agama dan kepuasan hidup (Seligman, 2002). Khavari (2006) berpendapat bahwa faktor yang mempengaruhikebahagiaan, yaituuang, kesuksesan, usia, jeniskelamin, kecerdasan, komunitas, seks, kesehatan, kebersamaan, agama, cinta, perkawinan, kepuasan kerja, dan kebahagiaan batin.

Uang sebagai salah satu faktor yang mempengaruhi kebahagiaan seseorang, tetapi jika seseorang menempatkan uang sebagai tujuan utama akan menyebabkan individu kurang puas terhadap pemasukan lainnya. Seligman (2005), menyimpulkan penilaian seseorang terhadap uang akan mempengaruhi kebahagiaannya lebih daripada uang itu sendiri. Pernikahan memiliki dampak yang jauh lebih besar dibanding uang dalam mempengaruhi kebahagiaan seseorang. Penelitian yang dilakukan oleh Seligman dan Diener (dalam Seligman, 2005) menemukan hampir semua orang dari $10 \%$ orang yang paling bahagia memiliki hubungan romantis dengan orang lain. Orang yang sangat bahagia menjalani banyak kehidupan sosial dan jarang menghabiskan waktu sendirian.

Selanjutnya faktor budaya dan sosial politik mempengaruhi tingkat kebahagiaan seseorang (Carr, 2004). Hasil penelitian lintas budaya menjelaskan bahwa hidup dalam suasana demokrasi yang sehat dan stabil lebih membahagiakan daripada suasana pemerintahan yang penuh dengan konflik militer. Budaya dengan kesamaan sosial memiliki menyebabkan individu memiliki tingakat kebahagiaan yang lebih tinggi. Kebahagiaan juga lebih tinggi pada masyarakat yang memiliki kebudayaan individualitas dibandingkan dengan kebudayaan kolektivistis.

Berdasarkan uraian tersebut, kebahagiaan seseorang tidak hanya ditentukan oleh faktor diri sendiri. Tidak semua faktor tersebut memiliki porsi yang sama dalam mempengaruhi kebahagiaan. Usaha atau aktivitas yang dilakukan dalam mencapai kebahagiaan dapat berbeda-beda pada setiap individu, karena berkaitan dengan pemahaman dan konsep orientasi kebahagiaan yang dimiliki oleh masing-masing individu tersebut. Seligman (2002) menyatakan bahwa terdapat kecenderungan seseorang untuk bergantung pada satu orientasi kebahagiaan daripada yang lain. Selain itu, orientasi kebahagiaan juga dapat mempengaruhi tindakan dan pilihan aktivitas yang dilakukan individu (Peterson \& Seligman, 2004). Adapun yang disebut sebagai orientasi kebahagiaan oleh Seligman (2002) adalah preferensi seseorang untuk mencapai kebahagiaan.

Berdasarkan penelitian Peterson \&Seligman (2004), terdapat tiga elemen orientasi kebahagiaan yaitu emosi positif, engagement, dan kebermaknaan. Orang-orang dengan orientasi kebahagiaan pada elemen emosi positif lebih berfokus pada mencapai kesenangan (pleasure) dan menghindari halhal yang menyakitkan atau berpotensi menimbulkan penderitaan. Orientasi terhadap elemen engagement dapat diperoleh dengan melibatkan diri dalam aktivitas-aktivitas yang sesuai dengan kompetensi dan minat, sehingga individu dapat menikmati setiap aktivitasnya dan memiliki keterlibatan dengan hal tersebut. Sedangkan elemen kebahagiaan meaning menunjukkan kecenderungan seseorang untuk melakukan suatu hal berdasarkan kebermaknaan suatu hal tersebut bagi dirinya dan sesuatu yang lebih besar dari diri individu tersebut. 
Berdasarkan uraian di atas, pertanyaan penelitian ini adalah Bagaimana orientasi happiness pada ibu yang memiliki anak tunagrahita ringan?. Bagaimana orientasi happiness pada ayah yang memiliki anak tungrahita ringan?.

\section{METODE}

Penelitian ini merupakan penelitian kualitatif dengan menggunakan pendekatan studi kasus. Sesuai dengan pendapat Creswell (2010) digunakan dalam penelitian karena peneliti menganggap ada yang unik dalam kehidupan ayah dan ibu yang memiliki anak tuna grahita ringan. Fokus penelitian adalah orientasi happines ibu dan ayah yang memiliki anak tunagrahita ringan, yaitu dikaji dari tiga tema yaitu, sesuatu yang menyenangkan, partisispasi sosial, kebermaknaan hidup. Metode pengumpulan data menggunakan wawancara. Analisis data menggunakan teknik interaktif.

Subjek penelitian dipilih secara purposive. Informan primer adalah ibu dan ayah yang memiliki anak tuna grahita ringan yang bersekolah di SLB C Yakut Purwokerto, sedangkan informan sekunder adalah tetangga. Adapun profil informan disajikan pada tabel 1 .

Tabel 1. Data demografi informan primer

\begin{tabular}{lcc}
\hline \multicolumn{1}{c}{ Data } & Ibu & Ayah \\
\hline Usia (tahun ) & & \\
\hline $25-30$ & $10 \%$ & 0 \\
$31-35$ & $40 \%$ & 0 \\
$36-40$ & $20 \%$ & $10 \%$ \\
$41-45$ & $10 \%$ & $40 \%$ \\
$46-50$ & $10 \%$ & $30 \%$ \\
$51-55$ & $10 \%$ & $20 \%$ \\
\hline Pendidikan akhir & & \\
\hline Sekolah Dasar & $50 \%$ & $40 \%$ \\
SLTP & $30 \%$ & $40 \%$ \\
SLTA & $20 \%$ & $20 \%$ \\
\hline Pekerjaan & & \\
\hline Ibu Rumah Tangga & $90 \%$ & \\
Buruh & $10 \%$ & $20 \%$ \\
Petani & & $10 \%$ \\
Sopir & & $10 \%$ \\
Pegawai swasta & & $40 \%$ \\
Penjahit & & $10 \%$ \\
\hline
\end{tabular}

Berdasarkan tabel 1, dapat dilihat bahwa sebagian besar informan ayah berusia 41-45 tahun. Jika dilihat dari tingkat pendidikan menunjukkan bahwa pendidikan ibu lebih rendah dari pendidikan ayah. Perbedaan tingkat pendidikan menyebabkan perbedaan pengetahuan. Semakin tinggi tingkat pendidikan, semakin mudah orangtua menerima serta mengembangkan pengetahuan dan teknologi, sehingga akan meningkatkan pengetahuan tentang pengasuhan dan kesejahteraan keluarga (Notoatmodjo, 2003). Tabel tersebut juga menunjukkan bahwa sebagian besar ibu sepenuhnya sebagai ibu rumah tangga. Sebagian besar informan suami adalah pegawai swasta, buruh dan penjahit. Para informan termasuk golongan pendapatan sedang, padahal besarnya pendapatan keluarga akan menentukan sumber kebahagiaan dalam kehidupan berkeluarga.

\section{HASIL DAN PEMBAHASAN}

Analisis data mengikuti pendapat Creswell (2010) yaitu : 1) Membuat rincian deskripsi tematis kasus orientasi happiness ayah dan ibu yang memiliki anak tunagrahita ringan, 2) Membuat agregasi kategori dengan mengelompokkan tema, 3) Membuat penafsiran langsung terhadap data dengan membuat pola dan mencari hubungan antar kategori, 4) Mengembangkan generalisasi pola orientasi happiness ayah dan ibu yang memiliki anak tuna grahita ringan serta menghadapkannya dengan teori orientasi happiness. Berdasarkan analisis data peneliti mendapatkan tema orientasi happiness yang menunjukkan bagaimana informan mencapai kebahagiaan, yaitu : 1) Sesuatu yang menyenangkan, 2) Keterlibatan sosial, 3) Kebermaknaan hidup.

Uraian setiap tema pada informan ibu adalah sebagai berikut :

Sesuatu yang menyenangkan

Informan P4, P6 dan P9 berusaha mencapai kebahagiaan dengan cara mengajak anak jalan-jalan, memenuhi kebutuhan makanan, 
dan memberikan mainan yang banyak. Keyakinan bahwa barang dan uang adalah jalan utama untuk mencapai kebahagiaan personal. Seorang materialis mengejar kebahagiaan lewat pemenuhan kebutuhan kebendaan di bandingkan dengan cara yang lain, seperti hubungan sosial, pengalaman, atau prestasi (Richins \& Dawson, 1992). Menurut Seligman (2002), di negara-negara miskin, uang dianggap sebagai jalan menuju kebahagiaan, sebaliknya di negara makmur, uang bukan ukuran kebahagiaan. Berkaitan dengan penelitian ini, semua informan berasal dari keluarga dengan penghasilan yang kurang yaitu $40 \%$ menjadi pegawai swasta dengan penghasilan yang tidak tetap. Kondisi ini menyebabkan orientasi happiness pada pemenuhan kebutuhan paling dasar, yaitu makan dan kesenangan fisik lainnya.

\section{Keterlibatan sosial}

Informan memiliki orientasi happiness dengan cara melibatkan diri dalam aktivitasaktivitas yang sesuai dengan kemampuan dan minat, sehingga individu dapat menikmati setiap aktivitasnya dan terlibat aktif dalam aktivitas tersebut. Informan P2, P3 selalu aktif dalam kegiatan PKK dan dasa wisma. Informan aktif sebagai pengurus dan merasa bahagia karena diberi kepercayaan mengurus administrasi PKK. Informan aktif setiap kegiatan yang diadakan PKK, antara lain pertemuan bulanan, arisan, lomba keputrian dan mewakili RT setiap kali kegiatan PKK di tingkat kelurahan dan kecamatan. Informan memiliki pendidikan yang rendah, tetapi karena belajar sehingga bisa menguasai administrasi PKK. Keterlibatan di PKK tidak mengganggu aktivitas mengasuh anak, Informan tetap mengantar dan menjemput anak di sekolah. Informan merasa bahagia karena banyak teman dan merasa bisa diterima oleha teman-temannya. Informan P2 mendapatkan tempat untuk mencurahkan keluh kesahnya dengan teman sesama aktifis PKK. Informan P3 merasa mendapatkan banyak ilmu termasuk ilmu pengasuhan dengan sering mengikuti kegiatan PKK karena sering mendapatkan penyuluhan dari nara sumber.
P5, P7, P8 dan P10 aktif mengikuti kegiatan pengajian di lngkungannya. Dengan mengikuti kegiatan pengajian, informan merasa nyaman, karena ilmu yang didapatkan membuat informan lebih bersyukur dan bisa menerima anaknya sesuai dengan kekurangannya. Informan P8 dan P10 mengikuti kegiatan pengajian tidak hanya di lingkungannya, tetapi juga mengikuti di masjid kampung lain. Tujuannya adalah mendapatkan banyak ilmu dan banyak teman. Informan P5, P7, P8 dan P10 merasa bahagia karena teman-teman kelompok pengajiannya bisa menerima keadaan anaknya, tidak mengucilkan dan selalu support informan untuk memberikan pendidikan yang terbaik untuk anaknya.

Schueller \& Seligman (2010) menyatakan bahwa keterlibatan dalam aktivitas yang bermakna memiliki dampak yang kuat pada kesejahteraan individu, karena dapat meningkatkan sumber daya sosial dan psikologis, sedangkan mengejar kesenangan tidak membangun sumber daya. Keterlibatan dalam suatu aktivitas bisa mengarahkan individu untuk mencari kegiatan yang lebih menantang keterampilan mereka dan mengembangkan bakat dan minat (Csikszentmihalyi, 1990). Hasil penelitian ini menunjukkan bahwa aktivitas informan dalam kegiatan sosial bisa mengembangkan daya psycho sosialnya dan menjadikan informan cenderung bahagia.

\section{Kebermaknaan hidup}

Bagi informan P1 hidupnya bisa lebih berarti karena memiliki anak yang berkebutuhan khusus. Sebagai ibu, informan merasa dibutuhkan dan anaknya selalu bergantung padanya. Bagi informan, peran sebagai ibu bisa sepenuhnya dijalani karena setiap hari anaknya selalu dalam pengawasannya. Kesempatan menjadi ibu yang sebenarnya dirasakan informan pada saat mengasuh anaknya yang berkebutuhan khusus. Informan tidak pernah menyalahkan takdir atau menyalahkan keadaan, justru informan merasa bersyukur memiliki anak berkebutuhan khusus karena memberinya 
kesempatan berperan sebagai ibu yang sesungguhnya.

\section{Menurut Schueller \& Seligman (2010) orientasi kebahagiaan dengan cara meaningful life cenderung mengembangkan sumberdaya dalam jangka panjang, berbeda dengan orientasi bahagia pleasure yang hanya untuk kepentingan sesaat. Penelitian ini mendukung penelitian sebelumnya yang mengatakan bahwa pleasure, keterlibatan dalam kegiatan dan makna hidup berkorelasi dengan kesejahteraan. Kehidupan bermakna secara signifikan berkorelasi dengan kebahagiaan, kepuasan hidup, dan mempengaruhi sepanjang hidup (Steger, Oishi, \& Kashdan, 2007).}

Selanjutnya uraian setiap tema pada informan ayah adalah sebagai berikut :

\section{Sesuatu yang menyenangkan}

Informan L1, L3, L5, L6, L8 dan L9 merasa bisa memiliki kebahagiaan jika bisa memenuhi kebutuhan ekonomi keluarga, terutama kebutuhan anaknya yang tunagrahita. Bisa memenuhi kebutuhan anaknya merupakan sesuatu yang menyenangkan. Semua informan mengaku belum sepenuhnya bisa memenuhi kebutuhan berupa uang, karena penghasilan yang paspasan. Tetapi informan berusaha mendapatkan tambahan penghasilan agar keluarganya sejahtera. Informan L1, L3 dan L8 melalukan kerja sampingan untuk menambah income keluarga, Informan L5, L6 dan L9 sering lembur agar dapat tambahan penghasilan.

Apa yang dilakukan informan merupakan salah satu bentuk pengasuhan ayah terhadap anak. Seperti pendapat Bart (1994) yang menyatakan bahwa dukungan fiansial dalam kajian psikologi sosial termasuk dalam aspek-aspek dukungan sosial. Dukungan sosial merupakan transaksi interpersonal yang melibatkan satu atau lebih aspek-aspek antara lain barang, pelayanan, dukungan keuangan, menyediakan peralatan yang dibutuhkan, memberikan bantuan dalam melaksanakan berbagai aktivitas, memberi peluang waktu, serta modifikasi lingkungan. Dukungan ayah secara instrumental dalam perawatan merupakan penyediaan materi yang dapat memberikan pertolongan langsung seperti pinjaman uang, pemberian barang, makanan serta pelayanan. Bentuk dukungan ini dapat mengurangi stress karena anak dapat langsung memecahkan masalahnya yang berhubungan dengan materi. Jika dikaitkan dengan orientasi happiness, pemenuhan kebutuhan finansial merupakan orientasi pleasure, hanya untuk kesenangan sesaat sehingga kurang bisa menjamin kepuasan hidup. Menurut Schueller \&Seligman (2010) hal ini disebut kesejahteraan hedonis.

\section{Partisipasi sosial}

Temuan selanjutnya, informan L2 dan L4 merasa bahagia karena sering terlibat dalam kegiatan sosial di tempat kerjanya. Kegiatan ini membuat informan merasa memiliki teman yang bisa menerima dirinya apa adanya dan membuat informan merasa bermanfaat bagi sesama. Informan L7 sering terlibat dalam pengajian di masjid kampungnya. Informan merasa mendapatkan banyak ilmu dan bisa dijadikan dasar dalam mengasuh anaknya. Informan merasa nyaman jika berada di dalam kelompok pengajian, merasa bisa diterima dan merasa kemampuan mengajinya bertambah.

Csikszentmihalyi (1990) menggambarkan kesenangan (pleasure) sebagai orientasi yang penting namun tidak cukup untuk kebahagiaan karena tidak mempromosikan perkembangan psikologis. Sebaliknya, kehidupan yang baik adalah jika terlibat secara aktif melalui kegiatan yang berarti. Orientasi happiness dalam dimensi engagement, akan mempromosikan kehidupan masa depan yang lebih sejahtera, karena sumber daya psikososialnya meningkat.

\section{Kebermaknaan hidup}

Temuan selanjutnya, Informan L10 memiliki orientasi happiness dalam dimensi 
meaningful life, artinya informan lebih bahagia jika hidupnya penuh makna. Informan mencapai hidupnya lebuh bermakna jika mendapat kepercayaan dari orang lain, antara lain pelanggan, teman kerja, istri dan anaknya. Informan bekerja sebagai penjahit, sehingga merasa bahagia jika pelanggannya puas dengan jahitannya atau desainnya. Informan juga bisa lebih kreatif dengan pekerjaannya, bisa mengembanagkan kemampuan diri.

Hasil penelitian Schueller \& Seligman (2010) menunjukkan bahwa orientasi engagement dan meaningful life menjadi sumber yang paling penting untuk mencapai kesejahteraan hidup. Orientasi ini akan membantu hidup informan untuk mencapai tujuan hidup yang lebih bermakna.

\section{SIMPULAN}

Terdapat perbedaan pola orientasi happiness antara ibu dengan ayah yang memiliki anak tunagrahita. Orientasi kebahagiaan ibu lebih didominasi pada keterlibatan sosial, artinya ibu lebih berbahagia jika bisa terlibat dalam aktivitas sosial. Sedangkan ayah mencapai kebahagiaan jika bisa melakukan sesuatu yang menyenangkan yaitu dengan cara memenuhi kebutuhan ekonomi keluarga

\section{DAFTAR PUSTAKA}

Bart, S., (1994). Psikologi kesehatan. Jakarta: PT. Gramedia Widiasarana.

Cabrera, N., Tamis-Lemonda, C., Bradley, R., Hofferth, S. \& Lamb, M. (2000). "Fatherhood in the 21st century". Child Development, 71, (1) , 127136.

Carr, A. (2004). Positive psychology : The science of happiness and human strengths. Hove \& NewYork : Brunner - Routledge Taylor \& Francis Group.
Csikszentmihalyi, M. (1990). Flow: The psychology of optimal experience. New York: Harper \& Row.

Cohen, D.J., \& Volkmar, F.R. (1997). Handbook of autism and pervasive developmental disorders. 2th ed. USA: John Wiley \& Sons Inc.

Creswell, J.W. (2010). Research design. pendekatan kualitatif, kuantitatif dan mixed. Edisi Ketiga (Terjemahan). Yogyakarta : Pustaka Pelajar.

Diener, E., \& Oishi, S. (2005). Subjective well-being: The science of happiness and life satisfaction. In S. R. Snyder \& S. J. Lopez (Eds.), Handbook of Positive Psychology. Oxford: Oxford University Press.

Furnham, A., \& Fudge, C., (2008). The five factor model of personality and sales performance, Journal of Individual Differences, 29(1),11-16.

Hamid, A.Y. (2004). Pengalaman keluarga dan nilai anak tunagrahita. Diakses http://pusdiknakes.or.id/fikui/?show= detailnew \&kode $=25 \&$ tbl=pustaka pa da 16 Oktober 2014.

Khavari, K. A. (2006). The art of happiness. Jakarta : Serambi Ilmu Semesta.

Lyubomirsky, S. (2007). The how of happiness. New York : The Penguin Press.

Mangunsong, F. (2011). Psikologi dan pendidikan anak berkebutuhan khusus jilid kedua. Depok: LPSP3 UI.

Na'imah, T. \& Septiningsih, D.S., (2015), Pendidikan karakter untuk anak berkebutuhan khusus (Studi relasi gender pada keluarga yang memiliki anak tuna grahita ringan). Prosiding SnaPP,. I (1), 239-246. 
Notoatmodjo, S. (2003). Pendidikan dan perilaku kesehatan. Jakarta : Rineka Cipta.

Peterson, C., \& Seligman, M. E. P. (2004). Character strengths and virtues: $A$ handbook and classification. Washington, DC: American Psychological Association.

Richins, M. L., \& Dawson, S. (1992). A consumer values orientation for materialisme and its measurement: Scale development and validation. Journal of Consumer Research, 19(3), 303-316.

Schueller, S.M., \& Seligman, M., (2010), Pursuit of pleasure, engagement, and meaning: Relationships to subjective and objective measures of well-being, The Journal of Positive Psychology, 5, (4), 253-263.
Seligman, M. (2002). Authentic happiness: Using the new positive psychology to realize your potential for lastin $g$ fulfillment. New York: Free Press.

Seligman, M. (2005). Authentic happiness: Using the new positive psychology to realize your potential for lasting fulfillment (Eva Yulia Nukman, Penerjemah). Bandung: PT. Mizan Pustaka.

Soemantri, T.S., (2007), Psikologi anak luar biasa, Bandung : Refika Aditama.

Steger, M.F., Kashdan, T.B., \& Oishi, S. (2007). Being good by doing good: Daily eudaimonic activity and wellbeing. Journal of Research in Personality, 42 (2008), 22-42.

William, C., \& Wright, B. (2004). How to live with autism and asperger syndrome.(terjemahan), Jakarta: Dian Rakyat. 